\title{
A molecular genetic analysis of childhood nephrotic syndrome in a cohort of Saudi Arabian families
}

\author{
Mohamed H Al-Hamed ${ }^{1,2}$, Essam Al-Sabban ${ }^{3}$, Hamad Al-Mojalli ${ }^{3}$, Naffaa Al-Harbi ${ }^{3}$, Eissa Faqeih ${ }^{4}$, \\ Hammad Al Shaya ${ }^{4}$, Khalid Alhasan ${ }^{5}$, Safaa Al-Hissi ${ }^{1}$, Mohamed Rajab ${ }^{1}$, Noel Edwards ${ }^{2}$, Abbas Al-Abbad ${ }^{3}$, \\ Ibrahim Al-Hassoun ${ }^{3}$, John A Sayer ${ }^{2}$ and Brian F Meyer ${ }^{1}$
}

Nephrotic syndrome (NS) is a renal disease characterized by heavy proteinuria, hypoalbuminemia, edema and hyperlipidemia. Its presentation within the first 3 months of life or in multiple family members suggests an underlying inherited cause. To determine the frequency of inherited NS, 62 cases (representing 49 families with NS) from Saudi Arabia were screened for mutations in NPHS1, NPHS2, LAMB2, PLCE1, CD2AP, MYO1E, WT1, PTPRO and Nei endonuclease VIII-like 1 (NEIL1). We detected likely causative mutations in 25 out of 49 families studied (51\%). We found that the most common genetic cause of NS in our cohort was a homozygous mutation in the NPHS2 gene, found in 11 of the 49 families (22\%). Mutations in the NPHS1 and PLCE1 genes allowed a molecular genetic diagnosis in $12 \%$ and $8 \%$ of families, respectively. We detected novel MYO1E mutations in three families (6\%). No mutations were found in WT1, PTPRO or NEIL1. The pathogenicity of novel variants was analyzed by in silico tests and by genetic screening of ethnically matched control populations. This is the first report describing the molecular genetics of NS in the Arabian Peninsula.

Journal of Human Genetics (2013) 58, 480-489; doi:10.1038/jhg.2013.27; published online 18 April 2013

Keywords: consanguineous; mutation; nephrotic

\section{INTRODUCTION}

Nephrotic syndrome (NS) is a renal disease characterized by heavy proteinuria, hypoalbuminemia, edema and hyperlipidemia. ${ }^{1}$ Urinary losses of macromolecules such as albumin reflect a dysfunction of the highly permselective glomerular filtration barrier. $^{2}$ The glomerular filtration barrier structure consists of podocyte foot-process, glomerular basement membrane, endothelial fenestration and the slit diaphragm. The identification of mutations leading to defects in proteins highly expressed in the podocyte and slit diaphragm has helped to unravel the basis of glomerular filtration barrier physiology and pathophysiology. ${ }^{3}$ Kidney biopsies in NS patients may show nonspecific changes such as minimal change, as well as focal segmental glomerulosclerosis (FSGS) and diffuse mesangial sclerosis. ${ }^{4}$ A molecular genetic diagnosis is important for making treatment decisions including suitability for renal transplantation and to enable screening of other family members at risk of disease.

NS may be given a series of descriptive labels dependent on their age of presentation. Congenital NS (CNS) manifests in utero or during the first 3 months of life; infantile NS has an onset between 3 months and 1 year of age ${ }^{5}$ and childhood steroid-resistant NS (SRNS) may be defined as no urinary remission within 4 weeks of prednisone therapy $60 \mathrm{mg} \mathrm{m}^{-2}$ day $^{-1}{ }^{6}$ From a molecular genetics standpoint, NS may be grouped into several types, which are briefly reviewed here.

NS type 1(NPHS1) is an autosomal recessive disorder characterized typically by CNS and often followed by a rapid progression to endstage renal disease (ESRD). ${ }^{7}$ Affected children are usually born prematurely, with the mother having a large placenta. Hypoalbuminemia, hyperlipidemia, abdominal distention and edema appear soon after birth. Mutations in NPHS1 account for $\sim 50 \%$ of all cases of CNS. ${ }^{5,8}$ Electron microscopic studies of the affected kidney in murine models show effacement of the podocytes and absence of the slit diaphragm. ${ }^{9}$ The Fin $_{\text {major }}$ and Fin $_{\text {minor }}$ mutations in NPHS1 are seen in the majority of Finnish patients with CNS. ${ }^{7}$ Although NPHS1 mutations are considered the major genetic cause of CNS, it has also been shown CNS may be caused by mutations in other genes. ${ }^{10}$

NS type 2 (NPHS2) is an autosomal recessive disorder typically characterized by childhood SRNS, and may progress to end-stage renal disease (ESRD). ${ }^{11}$ Kidney biopsies may show nonspecific histologic changes such as minimal change, FSGS or diffuse mesangial proliferation. Some patients show a later onset of the disorder. ${ }^{12}$ Mutations in NPHS2 account for $42 \%$ of familial and $10 \%$ of sporadic cases of childhood SRNS and have also been found in $39 \%$ of patients with CNS. ${ }^{2}$

${ }^{1}$ Department of Genetics, King Faisal Specialist Hospital and Research Centre, Riyadh, Saudi Arabia; ${ }^{2}$ Institute of Genetic Medicine, Newcastle University, International Centre for Life, Newcastle, UK; ${ }^{3}$ Department of Pediatrics, King Faisal Specialist Hospital and Research Centre, Riyadh, Saudi Arabia; ${ }^{4}$ Department of Pediatrics, King Fahad Medical City, Riyadh, Saudi Arabia and ${ }^{5}$ Division of Pediatric Nephrology, King Saud University, King Khalid University Hospital, Riyadh, Saudi Arabia 
NS type 3 (NPHS3) has been described in patients with infantile NS and childhood SRNS whom show histological changes of diffuse mesangial sclerosis on renal biopsy. Mutations in PLCE1 underlie this condition. ${ }^{13,14}$

NS type 4 (NPHS4) is secondary to WT1 mutations, encoding the transcription factor Wilms' tumor-suppressor gene 1. As well as causing Wilms' tumor, Frasier syndrome and Denys Drash syndrome, WT1 mutations may cause NS and progression to renal failure. Histologically, the picture is usually diffuse mesangial sclerosis, but renal biopsies may show FSGS. ${ }^{15}$ WT1 mutations may cause SRNS in infants and children without features of Frasier syndrome ${ }^{16,17}$ and have been reported in up to $9 \%$ of such cases. Genetic screening of other cohorts, including African-American children with FSGS and SRNS $^{18}$ and Japanese children with $\mathrm{CNS}^{19}$ did not detect WT1 mutations.

NS type 5 (NPHS5) is characterized by CNS and very early-onset progressive renal failure. Some patients have associated ocular abnormalities including myopia, nystagmus and strabismus. ${ }^{20}$ Mutations in $L A M B 2$ underlie this type of NS. Severe eye disease, NS and developmental delay in association with $L A M B 2$ mutations is known as Pierson syndrome. ${ }^{21}$ Milder phenotypes with isolated renal disease have been described with homozygous and compound heterozygous missense mutations in LAMB2. ${ }^{20}$

NS type 6 (NPHS6) was recently described in two consanguineous families with childhood SRNS. ${ }^{22}$ The implicated gene is known as PTPRO.

Heterozygous mutations in CD2AP typically cause adult onset NS, with an autosomal dominant pattern of inheritance and lead to the histological diagnosis of FSGS. ${ }^{23}$ However, given its known interaction with nephrin ${ }^{24}$ and podocin ${ }^{25}$ it may also account for cases of childhood SRNS. Indeed, a homozygous CD2AP mutation in a child presenting at the age of 10 months has recently been described. ${ }^{26}$ In addition, a heterozygous CD2AP variant, together with a NPHS2 variant, has been found in a child presenting at 3 and a half years of age with SRNS and biopsy proven FSGS. ${ }^{27}$

Additional genes, some only very recently described, associated with NS include ACTN4, ${ }^{23}$ TRPC6, $^{28,29}$ INF2, ${ }^{30}$ and MYO1E. ${ }^{31}$ Recently, Nei endonuclease VIII-like 1 (NEIL1), which encodes a base-excision DNA repair enzyme and was postulated as a candidate gene for NS in a single consanguineous family. ${ }^{32}$ Its role in NS remains uncertain. Occasionally, NS may be part of more complex syndromes and examples include Nail-Patella syndrome ${ }^{33}$ and Galloway-Mowat syndrome. ${ }^{34}$

In this study, we screened for mutations in nine genes implicated in inherited NS in a Saudi Arabian population with either CNS, infantile NS or childhood SRNS. Such a study has never been conducted for this part of the world. The Saudi Arabian population has a tribal structure and the overall rate of consanguineous marriage is reported to be over $55 \%$, with regional variations. ${ }^{35,36}$ In such a population, the identification of mutations in known recessive disease genes is an important consideration and we were interested in our ability to detect a molecular genetic cause of NS. Identification of a molecular genetic cause of NS allows both a definitive diagnosis and improved clinical management of the patient and at risk relatives. It is noteworthy that the Saudi population is at high risk of renal failure, with 133 incident cases per million population per year that require renal replacement therapy. ${ }^{37,38}$

We identified 62 cases, representing 49 families with CNS, infantile NS or childhood SRNS and undertook mutational analysis in known and candidate NS genes. We found a high rate of mutations in this cohort, solving $51 \%$ of cases. Direct sequencing identified novel and likely pathogenic genetic variants in NPHS1, NPHS2, $M Y O 1 E$ and PLCE1, increasing the known spectrum of mutations in these genes.

\section{MATERIALS AND METHODS}

\section{Study cohort}

This study has been approved by the research advisory council of King Faisal Specialist Hospital, Riyadh, Saudi Arabia (RAC\#2050 045). Following informed consent, DNA was extracted from peripheral blood cells using the Gentra Systems PUREGENE DNA Isolation kit. A total of 62 samples from 49 different families were obtained. Altogether, 25 samples were obtained from 12 families with evidence of familial NS and 37 samples were obtained from families with a single affected individual with NS. Clinical phenotypes included patients with CNS, infantile NS and childhood SRNS. Consanguineous marriages were noted. Clinical data and biopsy reports were reviewed where available.

\section{Mutation analysis}

Mutational screening was undertaken of known genes implicated in NS; NPHS1 (RefSeq NM_004646.3), NPHS2 (RefSeq NM_014625.2), LAMB2 (RefSeq NM_002292.3), PLCE1 (RefSeq NM_016341.3), CD2AP (RefSeq NM_ 012120.2), MYO1E (RefSeq NM_004998.3), WT1 (RefSeq NM_000378.4), PTPRO (RefSeq NM_030667.2) and NEIL1 (RefSeq NM_001256552.1). Direct sequencing of all coding exons and exon-intron boundaries was performed. Oligonucleotide primers for PCR amplification of genomic DNA were designed using Primer3 software (http://frodo.wi.mit.edu/) and synthesized by Metabion International AG (Munich, Germany). Primer sequences are available on request. PCR was performed in a final volume of $25 \mu \mathrm{l}$ containing approximately $20 \mathrm{ng}$ of genomic DNA and Qiagen (Manchester, UK) master mix kit (including $1 \mathrm{X}$ PCR buffer, $100 \mu \mathrm{moll}^{-1} \mathrm{dNTP}$, pair, and $1 \mathrm{U}$ per reaction HotStar Taq polymerase) and $0.5 \mu \mathrm{moll}^{-1}$ primer. PCR products were treated with the Agencourt AMPure PCR purification system (Agencourt Bioscience Corporation, Beverly, MA, USA). PCR products were sequenced using BigDye Terminator Cycle Sequencing kit (PE Applied Biosystems, Beverly, MA, USA) as described by the manufacturer. Sequences were analyzed using Mutation Surveyor software Version 3.24 (SoftGenetics LLC, State College, PA, USA) and SeqMan II software 6.1 (DNAStar, Madison, WI, USA),

Computational analyses of novel missense mutations were performed with PolyPhen-2 (http://genetics.bwh.harvard.edu/pph2/), Sorting Tolerant From Intolerant (SIFT) (http://sift.jcvi.org/) and SNPs3D (single nucleotide polymorphism resource found at http://www.snps3d.org/). PolyPhen-2 scores range from 0 to 1 , the higher the score the more damaging the amino-acid substitution. SIFT scores range from 0 to 1 . The amino-acid substitution is predicted damaging is the score is $\leqslant 0.05$, and tolerated if the score is $>0.05$. For SNPs3D, a positive score indicates a variant classified as non-deleterious, and a negative score indicates a deleterious case.

To assess splicing effects we used the GeneSplicer software (http:// www.cbcb.umd.edu/software/GeneSplicer/gene_spl.shtml). In addition to database searches, a control DNA panel from 175 individuals from a Saudi Arabian population was used to screen for all novel sequence variants.

Human MYOIE (accession number NP_004989) was modelled using the crystal structure of myosin-IE from Dictyostelium discoideum (protein data bank accession code, 1LKX). ${ }^{39}$ The Modeller program ${ }^{40}$ was used to create a three-dimensional model of MYOIE using the amino-acid sequence alignment generated through HHPred. ${ }^{41}$ Figures were prepared using PyMOL (http:// www.pymol.org/).

\section{RESULTS}

Sixty-two individual cases affected with CNS, infantile NS, childhood SRNS representing 49 families from the Arabian peninsula (Table 1) were screened for mutations in the following genes: NPHS1, NPHS2, LAMB2, PLCE1, MYO1E, WT1, PTPRO, NEIL1 and CD2AP. We identified mutations known NS genes in 9 out of 12 families (75\%) where there was reported to be $>1$ affected member with NS, suggesting an inherited cause (Table 1). A molecular genetic diagnosis was obtained in $43 \%$ (16 out of 37 ) of families with a single affected 
Table 1 Clinical summary of Saudi Arabian nephrotic syndrome cases

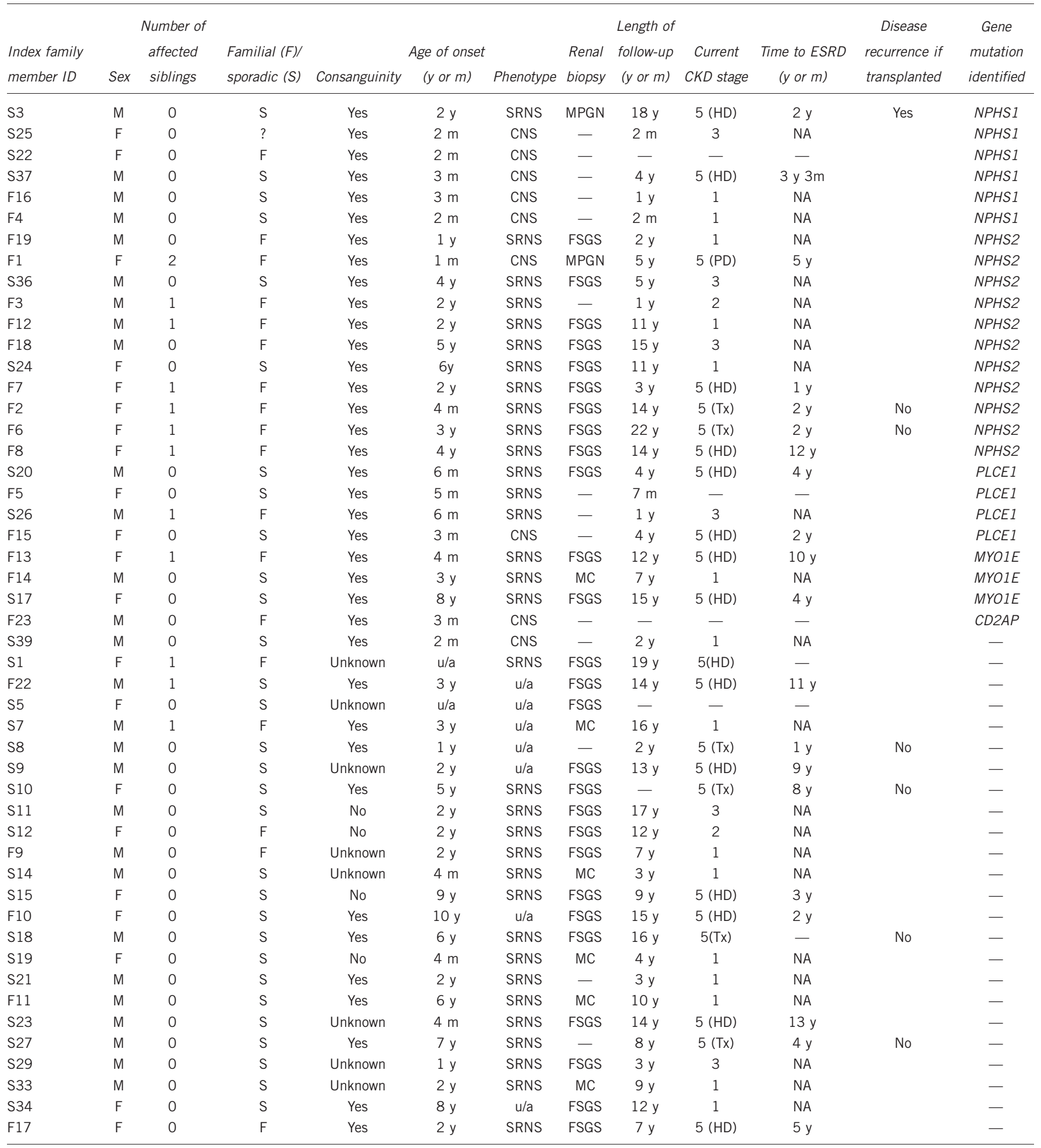

Abbreviations: CKD, chronic kidney disease; CNS: congenital nephrotic syndrome; ESRD, end-stage renal disease; F, female; FSGS, focal segmental glomerulosclerosis; HD, hemodialysis; M, male; m, month; MC, minimal change disease; MPGN, membranoproliferative glomerulonephritis; NA, not applicable; PD, peritoneal dialysis; SRNS, steroid resistance nephrotic syndrome; Tx, transplanted; u/a, unavailable; y, year.

member with NS. All families in whom we detected mutations had a history of consanguinity, most commonly first cousin marriages. Overall, in this population, by screening nine genes implicated in inherited NS we established a likely molecular genetic cause in $51 \%$ of families (Figure 1, Tables 1 and 2). No mutations were found in WT1 following screening of exons 8 and 9, NEIL1 or PTPRO by screening all coding exons. In this Saudi Arabian cohort, mutations in the NS genes NPHS2, NPHS1 and PLCE1 account for 22\%, 12\% and $8 \%$ of 
cases, respectively, of NS (Figure 1). Mutations in NPHS2 represent over two-fifths of genetically proven NS in this population.

The unsolved families (Table 1) had a reduced incidence of consanguinity, making the likelihood of sporadic NS higher in this group. Comparing the clinical phenotypes of the groups of NS

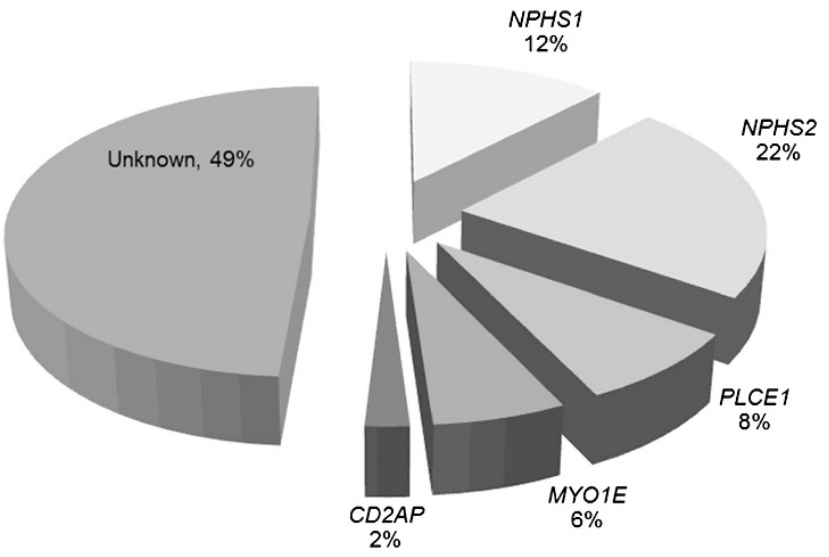

Figure 1 Molecular analysis of cohort of 49 families with congenital nephrotic syndrome (CNS) and steroid-resistant nephrotic syndrome (SRNS). In all, $51 \%$ of families ( 25 out of 49 ) had a positive molecular diagnosis in 1 of 5 genes, including NPHS1 (6 of 49), NPHS2 (11 of 49), PLCE1 (4 of 49), MYO1E (3 of 49) and CD2AP (1 of 49). patients who had a molecular genetic diagnosis compared with those that remain unsolved, there were similar rates of end-stage renal disease (ESRD) but CNS was a much more common finding in the solved cohort. There was a wide spread of age of onset and histological phenotypes in both groups of patients.

Previously published data from a world-wide cohort suggested that $\sim 50 \%$ of CNS is caused by mutations in NPHS1. ${ }^{8}$ In our cohort, mutations in NPHS1 accounted for five out of eight cases $(62.5 \%)$ of CNS, which had a confirmed molecular genetic diagnosis.

Of the novel homozygous sequence variants in coding regions (Table 3 and Figure 2), we identified three novel nonsense mutations, a donor splice site mutation with a high likelihood of aberrant splicing and two missense mutations. In silico predictions suggested that these missense changes are pathogenic (Table 3). A detailed analysis of the results for each gene is given below.

\section{NPHS1}

In this gene, we found six families carrying $\operatorname{known}^{7,42,43}$ or predicted pathogenic mutations. Five of the mutations were found in the homozygous state, and one (S22) was a compound heterozygous mutation involving two previously reported variants P368L and $\mathrm{R}_{460 \mathrm{Q}}{ }^{43}$ (Table 2). Here, segregation of the mutation from each parent was confirmed (data not shown). None of our cohort had Fin $_{\text {major }}$ (nt121delCT, L41fsX91) or Fin minor (c.3325C > T, R1109X) mutations. ${ }^{7}$ The affected patient from family S3 had a homozygous frame shift mutation in NPHS1 combined with a novel heterozygous NPHS2 (c.761G > T; p.C254F) allele (Tables 2 and 4). A p.P264R

Table 2 Cases with mutations identified in disease-associated genes

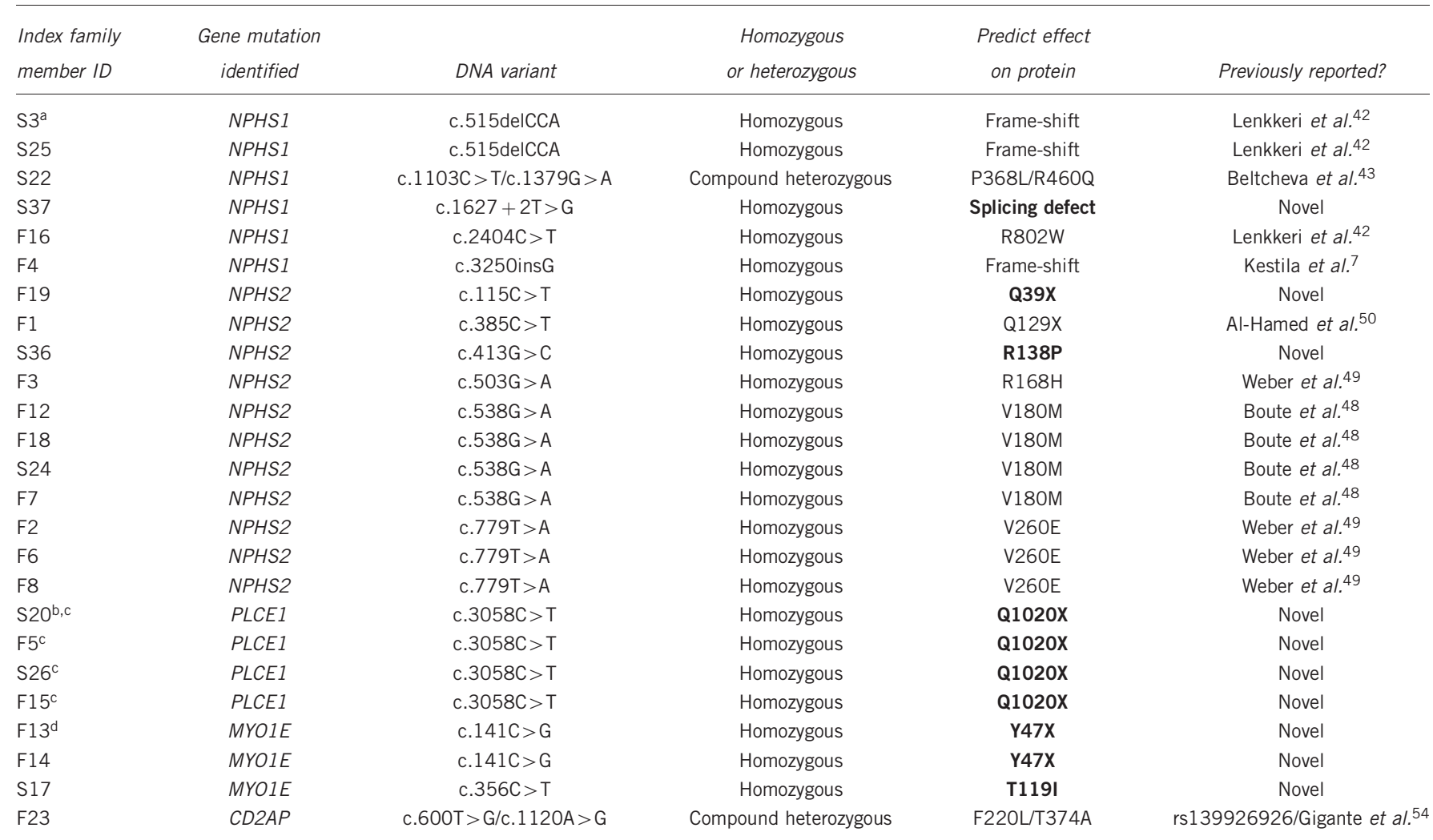

aFamily S3 also has a novel heterozygous NPHS2 c.761G > T C254F allele (see Table 4).

bFamily S20 also has a novel NPHS1 heterozygous variant c. $840+6 \mathrm{G}>\mathrm{A}$ (see Table 4).

cFamily S20, F5, S26 and F15 all have a novel homozygous PLCE1 intronic variant $4665+52 \mathrm{G}>\mathrm{C}$ (see Table 3 ).

'Family F13 also has a known NPHS2 heterozygous variant (see Table 5). Novel predicted effect on protein changes are shown in bold. 
Table 3 Novel genetic variants detected in NPHS1, NPHS2, PLCE1 and MYO1E and in silico analysis of pathogenicity

\begin{tabular}{|c|c|c|c|c|c|c|c|c|}
\hline Gene & $\begin{array}{l}\text { Homozygous } \\
\text { nucleotide } \\
\text { change }\end{array}$ & $\begin{array}{l}\text { Segregation } \\
\text { from } \\
\text { parents }\end{array}$ & $\begin{array}{c}\text { Amino-acid } \\
\text { change }\end{array}$ & PolyPhen-2 & SIFT & SNPS3D & $\begin{array}{c}\text { Allele frequency in } \\
\text { Saudi population } \\
\text { (\%) }\end{array}$ & $\begin{array}{c}\text { Expected } \\
\text { pathogenicity }\end{array}$ \\
\hline NPHS1 & $1627+2 T>G$ & Yes & $\begin{array}{c}\text { Predicted splicing } \\
\text { defect }\end{array}$ & NA & NA & NA & 0 & Pathogenic \\
\hline NPHS2 & c. $115 \mathrm{C}>\mathrm{T}$ & NA & Q39X & NA & NA & NA & 0 & Pathogenic \\
\hline NPHS2 & c. $413 G>C$ & NA & R138P & $\begin{array}{c}\text { Probably damaging } \\
(1.00)\end{array}$ & $\begin{array}{c}\text { Damaging } \\
\text { (0) }\end{array}$ & $\begin{array}{c}\text { Deleterious } \\
(-1.28)\end{array}$ & 0 & Pathogenic \\
\hline $\begin{array}{l}\text { PLCE1 } \\
\text { MYO1E } \\
\text { MYO1E }\end{array}$ & $\begin{array}{l}\text { c. } 3058 \mathrm{C}>\mathrm{T} \\
\text { c. } 141 \mathrm{C}>\mathrm{G} \\
\text { c. } 356 \mathrm{C}>\mathrm{T}\end{array}$ & $\begin{array}{l}\text { Yes } \\
\text { Yes } \\
\text { NA }\end{array}$ & $\begin{array}{c}\text { Q1020X } \\
\text { Y47X } \\
\text { T119I }\end{array}$ & $\begin{array}{c}\text { NA } \\
\text { NA } \\
\begin{array}{c}\text { Probably damaging } \\
(1.00)\end{array}\end{array}$ & $\begin{array}{c}\text { NA } \\
\text { NA } \\
\text { Damaging } \\
(0)\end{array}$ & $\begin{array}{c}\text { NA } \\
\text { NA } \\
\text { Deleterious } \\
(-2.65)\end{array}$ & $\begin{array}{l}0 \\
0 \\
0\end{array}$ & $\begin{array}{l}\text { Pathogenic } \\
\text { Pathogenic } \\
\text { Pathogenic }\end{array}$ \\
\hline
\end{tabular}

Abbreviation: NA, not available. SIFT, Sorting Tolerant From Intolerant; SNPs3D, single nucleotide polymorphism resource found at http://www.snps3d.org/. Novel predicted amino acid changes are shown in bold.

NPHS1

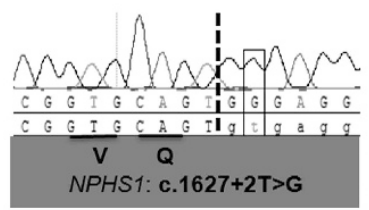

NPHS2

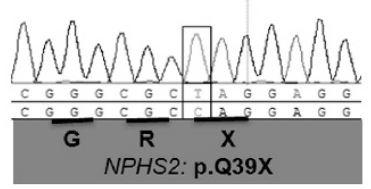

PLCE1

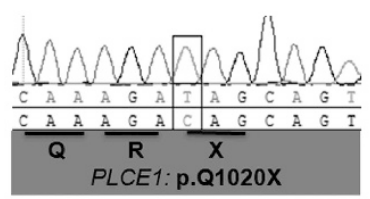

$\angle A M B 2$

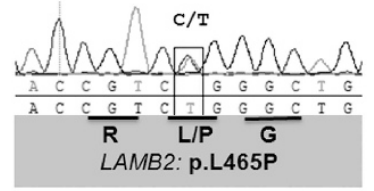

LAMB2

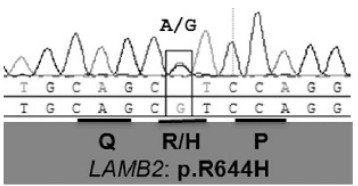

MYO1E

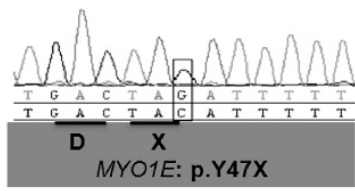

NEILI

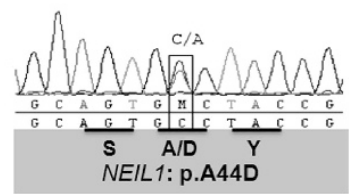

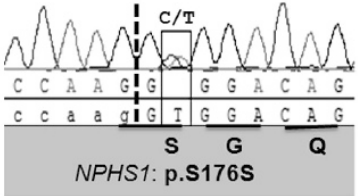
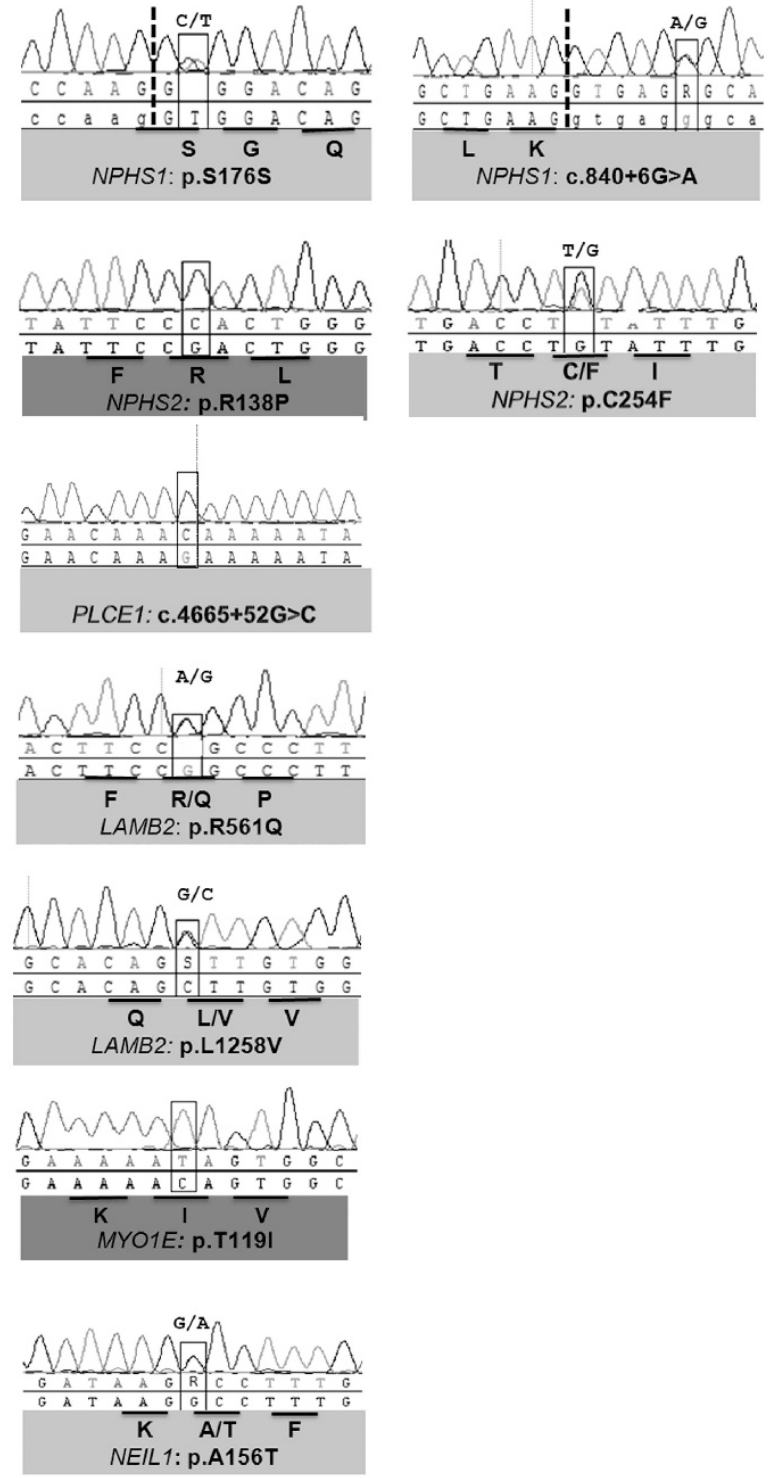

Figure 2 Sequencing chromatograms of novel genetic variants in patients with nephrotic syndrome (NS) from Saudi Arabia. Sequencing chromatograms are shown for novel sequence variants detected in NPHS1, NPHS2, PLCE1, LAMB2, MYO1E and NEIL1 in patients with NS. Sequence chromatograms are annotated with nucleotides, and reference nucleotide sequences shown below. The reading frame is indicated by black bars and amino-acid translations are given for exonic regions where appropriate. Exon-intron boundaries are marked with a vertical dashed line where appropriate. Likely pathogenic changes are colored red, whereas those of unknown or benign pathogencity are colored green. A full color version of this figure is available at the Journal of Human Genetics journal online. 
Table 4 Novel genetic variants of unknown significance and polymorphisms detected in NPHS1, NPHS2, LAMB2, NEIL1 and PLCE1

\begin{tabular}{|c|c|c|c|c|c|c|c|c|}
\hline Gene & Family ID & $\begin{array}{c}\text { Nucleotide } \\
\text { change }\end{array}$ & $\begin{array}{l}\text { Amino-acid } \\
\text { change }\end{array}$ & $\begin{array}{c}\text { Homozygous or } \\
\text { heterozygous }\end{array}$ & PolyPhen-2 & SIFT & SNPS3D & $\begin{array}{c}\text { Allele frequency in Saudi } \\
\text { population }\end{array}$ \\
\hline NPHS 1 & F22 & c. $528 \mathrm{~T}>\mathrm{C}$ & $\begin{array}{l}\text { S176S, possible } \\
\text { splicing defect }\end{array}$ & Heterozygous & NA & NA & NA & 0 \\
\hline NPHS1 1 & $\begin{array}{l}\mathrm{S} 20^{\mathrm{b}}, \mathrm{F} 9, \mathrm{~F} 17 \\
\mathrm{~S} 18, \mathrm{~S} 26^{\mathrm{b}}\end{array}$ & c. $840+6 \mathrm{G}>\mathrm{A}$ & $\begin{array}{l}\text { Intronic, possible } \\
\text { splicing defect }\end{array}$ & Heterozygous & NA & NA & NA & $1.15 \%$ \\
\hline NPHS2 & s3a & c. $761 \mathrm{G}>\mathrm{T}$ & $\mathrm{C} 254 \mathrm{~F}$ & Heterozygous & Benign (0.302) & $\begin{array}{l}\text { Tolerated } \\
(0.16)\end{array}$ & $\begin{array}{l}\text { Deleterious } \\
(-0.39)\end{array}$ & 0 \\
\hline$\angle A M B 2$ & S18 & c. $1393 \mathrm{~T}>\mathrm{C}$ & L465P & Heterozygous & Benign (0.137) & $\begin{array}{c}\text { Tolerated } \\
(0.35)\end{array}$ & $\begin{array}{l}\text { Non-deleter- } \\
\text { ious }(0.44)\end{array}$ & 0 \\
\hline$\angle A M B 2$ & F22 & c. $1982 \mathrm{G}>\mathrm{A}$ & R561Q & Heterozygous & $\begin{array}{l}\text { Probably dama- } \\
\text { ging }(0.994)\end{array}$ & $\begin{array}{l}\text { Tolerated } \\
(0.3)\end{array}$ & $\begin{array}{l}\text { Non-deleter- } \\
\text { ious }(0.91)\end{array}$ & $0.27 \%$ \\
\hline$\angle A M B 2$ & F17 & c. $1931 \mathrm{G}>\mathrm{A}$ & $\mathrm{R} 644 \mathrm{H}$ & Heterozygous & $\begin{array}{l}\text { Probably dama- } \\
\text { ging }(1.00)\end{array}$ & $\begin{array}{c}\text { Tolerated } \\
(0.44)\end{array}$ & $\begin{array}{c}\text { Deleterious } \\
(-1.16)\end{array}$ & $0.82 \%$ \\
\hline$\angle A M B 2$ & S11, S17 & c. $3772 \mathrm{C}>\mathrm{G}$ & L1258V & Heterozygous & $\begin{array}{c}\text { Possibly damaging } \\
(0.539)\end{array}$ & $\begin{array}{l}\text { Tolerated } \\
(0.38)\end{array}$ & $\begin{array}{l}\text { Non-deleter- } \\
\text { ious }(0.18)\end{array}$ & $0.55 \%$ \\
\hline NEILI & S9 & c. $131 \mathrm{C}>\mathrm{A}$ & A44D & Heterozygous & $\begin{array}{l}\text { Probably dama- } \\
\text { ging (0.999) }\end{array}$ & $\begin{array}{c}\text { Tolerated } \\
(0.37)\end{array}$ & $\begin{array}{l}\text { Non-deleter- } \\
\text { ious }(0.19)\end{array}$ & 0 \\
\hline$N E I L 1$ & S21 & c. $466 \mathrm{G}>\mathrm{A}$ & A156T & Heterozygous & Benign (0.217) & $\begin{array}{l}\text { Tolerated } \\
(0.33)\end{array}$ & $\begin{array}{l}\text { Non-deleter- } \\
\text { ious }(0.91)\end{array}$ & 0 \\
\hline PLCE1 & $\begin{array}{l}\mathrm{F} 5^{\mathrm{b}}, \mathrm{F} 15^{\mathrm{b}} \\
\mathrm{S} 20^{\mathrm{b}}, \mathrm{S} 26^{\mathrm{b}}\end{array}$ & c. $4665+52 G>C$ & Intronic & Homozygous & NA & NA & NA & 0 \\
\hline
\end{tabular}

Abbreviation: NA, not available. SIFT, Sorting Tolerant From Intolerant; SNPs3D, single nucleotide polymorphism resource found at http://www.snps3d.org/.

aFamily S3 also has a NPHS1 homozygous mutation (see Table 1)

bFamily F5, F15, S20 and S26 all have homozygous nonsense mutation in PLCE1 (see Table 1)

Table 5 Non-pathogenic sequence variants/polymorphisms identified in known nephrotic syndrome genes

\begin{tabular}{|c|c|c|c|c|c|c|}
\hline Gene & Family ID & $\begin{array}{c}\text { Nucleotide } \\
\text { change }\end{array}$ & Amino-acid change & $\begin{array}{c}\text { Homozygous or } \\
\text { heterozygous }\end{array}$ & $S N P I D$ & $\begin{array}{l}\text { Allele frequency in } \\
\text { Saudi population }\end{array}$ \\
\hline NPHS1 & S34, S39 & c. $791 C>G$ & P264R & Heterozygous & rs34982899 & NA \\
\hline NPHS2 & F13 & c. $709 \mathrm{G}>\mathrm{C}$ & E237Q & Heterozygous & rs146906190 & NA \\
\hline LAMB2 & S18, S29 & c. $5293 \mathrm{G}>\mathrm{A}$ & A1765T & Heterozygous & rs74951356 & NA \\
\hline LAMB2 & S20, S26 & c. $2099 \mathrm{G}>\mathrm{A}$ & G700E & Heterozygous & rs142860588 & NA \\
\hline LAMB2 & S39 & c. $3443 G>A$ & $\mathrm{R} 1148 \mathrm{H}$ & Heterozygous & rs138774635 & $0.82 \%$ \\
\hline PLCE 1 & $\mathrm{~F} 17$ & c. $6518 A>G$ & K2173R & Homozygous & rs111929795 & $0 \%$ \\
\hline$C D 2 A P$ & $\mathrm{~F} 5, \mathrm{~S} 14, \mathrm{~S} 16$ & c. $902 \mathrm{~A}>\mathrm{T}$ & K301M & Heterozygous & rs141778404 & $2.79 \%$ \\
\hline
\end{tabular}

Abbreviations: NA, not available; SNP, single-nucleotide polymorphism.

missense change was found in NPHS1 in two families (Table 5). This allele has previously been identified as contributing to a compound heterozygous mutation in NPHS1 in cases of severe CNS. $^{44,45}$ It has also been noted in cases of tri-allelic inheritance of steroid-resistant FSGS. ${ }^{27}$ The P264R variant has a minor allele frequency of $1 \%$ (rs34982899, dbSNP 1000 Genomes) and its pathogenicity is not proven. Indeed it has recently been classified as a polymorphism. ${ }^{46}$

One novel homozygous sequence variant was detected in the NPHS1 gene (S37 Tables 2 and 3). This sequence variant is predicted to be a splice site mutation affecting the $5^{\prime}$-splice donor site $(c .1627+2 \mathrm{~T}>\mathrm{G})$ predicting exon skipping of exon 12. Another novel heterozygous NPHS1 variant c.528T $>\mathrm{C}$ (p.S176S) is in a highly conserved region, and may affect splicing at the acceptor site, given that the $528 \mathrm{~T}$ nucleotide is the second nucleotide within exon 5 (Table 4). This variant was found in a heterozygous state in two patients from the same family (F22) in combination with a heterozygous missense change in LAMB2 (c.1982G > A; p.R561Q; Table 4).

Another novel heterozygous NPHS1 variant c.840+6G $>$ A was found in five families, two of whom also had a homozygous mutation p.Q1020X in PLCE1 gene (Tables 2 and 4). This NPHS1 c. $840+6 \mathrm{G}>\mathrm{A}$ variant was also found in $1.15 \%$ of our normal controls, suggesting it is unlikely to be pathogenic in isolation (Table 4).
Of the six families with homozygous or compound heterozygous NPHS1 mutations, five presented with CNS, whilst the other had a milder phenotypes, consistent with previous reports. ${ }^{47}$

\section{NPHS2}

Among our NS cohort there were 11 families with NPHS2 mutations (Tables 1 and 2). All mutations in affected individuals were in a homozygous state consistent with known parental consanguinity. Mutations detected in NPHS2 accounted for $44 \%$ of all the mutations detected in our cohort.

Four of the NPHS2 mutations had previously been reported ${ }^{48-50}$ and two novel homozygous NPHS2 mutations were detected. These included a nonsense mutation c.115C > T (p.Q39X), which is the most premature truncating mutation reported so far in NPHS2 and a missense mutation c.413G >C (p.R138P) in patients with SRNS. Of note, this arginine residue at position 138 (R138) of podocin has been the residue mutated in other cohorts, specifically p.R138Q and p.R138X. ${ }^{48}$ Both mutations, R138Q and R138X, were reported in SRNS patients. Indeed R138Q has been described as a founder mutation in European populations. ${ }^{48}$ Huber and et al. ${ }^{51}$ demonstrated that this mutation causes a failure to recruit nephrin into lipid rafts, providing important insights into the pathogenesis of this NPHS2 mutation. 

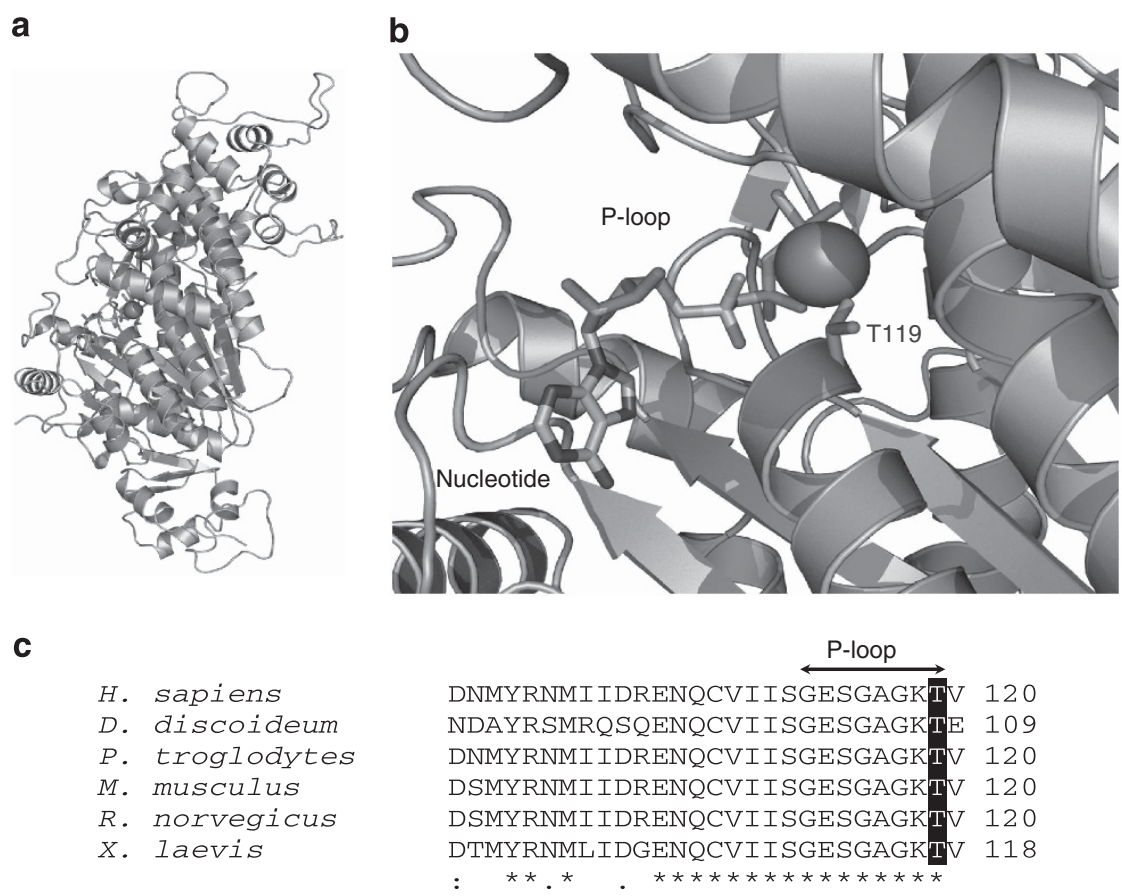

Figure 3 A homology model of MYO1E showing conservation of the P-loop motif. (a) Homology model of human MYO1E generated using the crystal structure of Dictyostelium discoideum myosin-IE (PDB $1 \mathrm{LKX}$ ) bound to MgADP.VO ${ }_{4}{ }^{39}$ The magnesium ion is shown as a magenta sphere. (b) Close-up of the nucleotide-binding domain of human MYOIE. The P-Ioop (112GESGAGKT ${ }^{119}$ ), together with the purine-binding loop, switch-1 and switch-2 (data not shown), comprise the nucleotide-binding site. The side-chain hydroxyl oxygen of T119 is shown in red. (c) Alignment of human MYOIE with various myosinIE orthologues. The conserved P-loop threonine residue at position 119 of MYOIE (shown in $\mathbf{b}$ ) is highlighted. A full color version of this figure is available at the Journal of Human Genetics journal online.

A novel heterozygous NPHS2 variant C254F was detected in a patient homozygous for a c.515delCCA mutation in NPHS1 gene (Tables 2 and 4). The variant $\mathrm{C} 254 \mathrm{~F}$ was not predicted to be definitely pathogenic by in silico models (Table 4) but neither was it found in our normal controls. This suggests that C254F could be a modifier allele.

Whilst screening our control population for novel NPHS2 variants, we observed a NPHS2 variant P20L (data not shown) in $2.32 \%$ of Saudi Arabian controls. This variant is of unknown functional significance $e^{52}$ and is rare in control European populations $s^{53}$ and was not associated with a NS disease phenotype, suggesting that this change should be considered as a rare polymorphism.

\section{PLCE1}

A novel homozygous mutation in PLCE1 (Q1020X) was detected in four families in our cohort, with a broad range of phenotypes (Tables 1 and 2). All affected individuals had the identical mutation, and segregation was confirmed in two of the families (F5 and F15, data not shown). This truncating mutation is predicted to have a severe affect on the PLCE1 protein with loss of the PLC catalytic domain, the protein kinase $\mathrm{C}$ conserved region and the Ras association domain. ${ }^{13}$ Interestingly, each of the Q1020X mutations in exon 7 of PLCE1 gene was associated with the variant $(c .4665+52 \mathrm{G}>\mathrm{C})$ in intron 18 (Table 4).

Affected and unaffected daughters in a family of African ancestry with SRNS (F17) were found to be homozygous for a rare variant (K2173R) in PLCE1 (Table 4). We did not find this variant in our Saudi Arabian control cohort. The affected F17 member was also heterozygous for novel variants c. $840+6 \mathrm{G}>\mathrm{A}$ in NPHS1 gene and $\mathrm{R} 644 \mathrm{H}$ in $L A M B 2$ gene (Table 4).

\section{MYO1E}

We detected novel homozygous MYO1E mutations in three families (Tables 1 and 2). All families presented with SRNS. In the first two families, renal biopsy revealed FSGS in one case, progressing to endstage renal disease by 10 years of age and minimal change disease, with preserved renal function in the other. The affected patients both had a Y47X nonsense mutation, segregating from each parent (data not shown). The Y47X is a severe truncating mutation, with a predicted loss of all functional domains of the MYO1E protein, including the motor-head domain, the calmodulin binding IQ domain and the tail domain. ${ }^{31}$ The affected female patient in family S17 presented at 8 years of age with SRNS and FSGS on renal biopsy and progressed to end-stage renal disease after 4 years (Table 1). She was found to have a T119I homozygous mutation (Table 2 and Figure 2). The threonine residue at position 119 is conserved throughout vertebrates (including zebrafish) and in the myosin-1d homolog of the amoeba Dictyostelium discoideum where it is the terminal residue of the P-loop motif (Figure 3).

\section{CD2AP}

A single patient presenting with CNS from family F23 in our NS cohort was found to have two known heterozygous variants in CD2AP (Tables 1 and 2). The first F220L is a variant of unknown significance (rs139926926), in a residue conserved to Danio rerio and was not detected in 350 healthy Saudi Arabian alleles. This variant was combined with T374A, a likely pathogenic mutation. ${ }^{54}$ The heterozygous T374A mutation in CD2AP was previously reported in a 2-year-old child presenting with SRNS and histological features of FSGS, and the missense change disrupts a proline-rich domain important for protein-protein interactions. ${ }^{54}$ 
In addition, the CD2AP variant $\mathrm{K} 301 \mathrm{M}$ was found as a heterozygous allele in three of our patients; one was associated with homozygous Q1020X mutation in PLCE1 gene (F5), other two (S14 and S16) were detected alone (Table 5). Although K301M has been reported by Gigante et al. ${ }^{54}$ previously as a pathogenic mutation, we also found this variant in $2.79 \%$ of our normal controls suggesting that this variant is a polymorphism. The previously reported CD2AP variant p.K301M was found a 23-year-old Italian female presenting with SRNS and FSGS. ${ }^{54}$ The same mutation was found in her 6-year-old child who was reported as phenotypically normal. Functional studies showed that at K301M variant had a defective CD2-CD2AP interaction. ${ }^{54}$ The high frequency of the K301M variant in the Saudi population would certainly point away from this heterozygous variant alone being disease causing.

We speculate that $C D 2 A P$ variants in the heterozygous state may increase susceptibility toward glomerular damage and proteinuria but until large-scale studies are conducted to elucidate the role of these variants, they remain of uncertain pathogenicity.

\section{LAMB2}

We found novel heterozygous LAMB2 sequence variants in five families from our cohort (Table 4). The affected patient in family S18 had a L465P heterozygous variant in LAMB2 gene together with an A1765T polymorphism in LAMB2; 55 (Tables 4 and 5). The L465P missense change is novel, and was absent from control samples, but predicted to be benign using in silico testing (Table 4).

In another family (F22), two affected patients (brothers) with FSGS had a single heterozygous R561Q variant in LAMB2. This novel variation of unknown severity was present in $0.27 \%$ of healthy controls and was in combination with a novel heterozygous NPHS1 S176S variant, predicted to have some deleterious impact on splicing (Table 4).

Additional novel (and likely polymorphic) variants were detected in the LAMB2 gene (Table 4; Figure 2). A heterozygous L1258V missense variant was detected in two families and also detected in $0.55 \%$ of our normal controls. The variant $\mathrm{R} 644 \mathrm{H}$ was detected in one allele of our patients and in $0.82 \%$ of normal controls.

Family S39 had a known heterozygous variant in LAMB2 (c.3443G > A; p.R1148H) in association with a heterozygous $\mathrm{P} 264 \mathrm{R}$ NPHS1 polymorphism (Table 5). This R1148H LAMB2 variant was found also in $0.82 \%$ of our normal controls (Table 5 ).

\section{DISCUSSION}

This study is the first to describe the molecular basis of NS in a Saudi Arabian population. Despite finding a high rate of mutations in known NS genes within our cohort (51\%), these findings suggest there are other novel genetic causes of NS yet to be discovered. The genetic heterogeneity underlying NS, even in this highly consanguineous population, is evident. It is noteworthy that all patients with identified mutations in NS-associated genes were from consanguineous marriages and most of the pathogenic mutations identified were in the homozygous state. There were two families (S22 and F23) where we identified compound heterozygous mutations in NPHS1 and $C D 2 A P$, respectively. Thus, reliance on screening genes in homozygous regions alone in known consanguineous families may miss compound heterozygous changes in relevant genes. Our experience is not unique. Using a homozygosity mapping approach in 12 families from different backgrounds with CNS, Schoeb et al. ${ }^{8}$ solved just five families by detecting homozygous mutations in NPHS1. A more systematic search, including all known NS genes, is therefore important for achieving a high mutation detection rate.
Although large deletions of genomic DNA have not previously reported for NPHS1, NPHS2, LAMB2, PLCE1, CD2AP, MYO1E and $P T P R O$, additional genetic analysis specifically looking for these may improve mutation detection rates. Large deletions in WT1 have been previously reported, ${ }^{56}$ but were exclusively associated with a Wilms' tumor phenotype rather than NS.

A strategy of targeted gene sequencing for patients manifesting NS in the first year of life in a world-wide study has previously been reported, and noted that two-thirds of patients could be explained by mutations in one of four genes (NPHS1, NPHS2, WT1 or LAMB2). ${ }^{5}$ In the modern era of whole-exome sequencing and targeted gene capture and sequencing, these approaches will allow mutations in known NS genes and novel NS genes to be detected with greater efficiency.

In our study, which included families with CNS, infantile NS and childhood SRNS, following molecular analysis of nine known NS genes, mutations were detected in around $51 \%$ of cases, which is comparable to the mutation detection rate in SRNS by other groups. ${ }^{57}$ Cohorts of more restricted phenotypes have identified mutations $\sim 80 \%$ of cases (non-Finnish CNS) by a systematic screen of implicated genes. ${ }^{46}$ Our mutation detection rate was, as one might predict, higher in patients where there was evidence of familial disease ( $>1$ affected member; $75 \%$ ) than in single individuals with NS (43\%).

Mutations in NPHS2 gene are the most frequent identified genetic cause of NS in our Saudi Arabian cohort, accounting for 44\% of all pathogenic mutations detected, in comparison with $\sim 40 \%$ of a European cohort, ${ }^{5}$ and $\sim 30 \%$ in a large Turkish study. ${ }^{58}$ Common NPHS2 mutations in our cohort included missense mutations V260E and V180M. All cases with mutations in NPHS2 presented with childhood SRNS, except one family (F3) that had CNS in association with a NPHS2 R168H mutation. All mutations detected in NPHS2 were homozygous, consistent with parental consanguinity in these cases.

NPHS1 mutations were detected, as expected, mainly in patients presenting with CNS patients. One case presented with childhood SRNS

In PLCE1 gene, we found one mutation common to four families with NS patients. Each of these families were descendants from large Saudi Arabian tribes. In Saudi Arabia, eight tribes account for around $10 \%$ of the country's population. The association of the Q1020X in PLCE1 with the intronic variant (c. $4665+52 \mathrm{G}>\mathrm{C})$ in PLCE1 in each of these cases may indicate a founder effect (Table 4).

The original description of MYO1E mutations identified just two consanguineous families with missense mutations A159P and nonsense mutation Y695X, originating from Italy and Turkey, respectively. ${ }^{31}$ No mutations in MYO1E were identified in a screen of sporadic cases of FSGS, ${ }^{31}$ suggesting that MYO1E is an uncommon cause of NS, but its true incidence, especially in populations of high consanguinity has yet to be determined There have been no other reports of MYO1E mutations to date. Here, by identifying two novel MYO1E mutations in an Arabic consanguineous population, we confirm the pathogenicity of MYO1E in NS and expand the spectrum of mutations in this rare cause of NS.

Most of the mutations previously reported in the CD2AP gene have been heterozygous changes, except in one case with biopsy proven FSGS where a homozygous mutation was found. ${ }^{26}$ In our cohort, we identified a single patient from a consanguineous family harboring a compound heterozygous mutation $(\mathrm{F} 220 \mathrm{~L} / \mathrm{T} 374 \mathrm{~A})$ in the CD2AP gene. In a previously published cohort of 35 families with SRNS in whom NPHS1, NPHS2 and PLCE1 mutations had been previously 
excluded, no CD2AP mutations were identified, confirming their rarity. ${ }^{59}$

We found one case (S3), presenting as SRNS, where a previously reported homozygous mutation (c.515delCCA) in $N P H S 1^{42}$ was associated with a heterozygous missense change (c.761G $>$ T; C254F) in NPHS2. This emphasizes the need to screen multiple NS-associated genes, even within a consanguineous pedigree, to determine modifier gene effects. The presence of triallelism in NS has been noted before ${ }^{44,45,60}$ and additional alleles in NS genes may modify the renal phenotype and the clinical presentation and course. Weber et al. ${ }^{49}$ described a child with CNS in whom a combination of a heterozygous de novo splice mutation in NPHS1 and a homozygous NPHS2 R138Q mutation was detected.

We were extremely careful not to define all the variants we have detected as pathogenic mutations, although many of them were found in $<1 \%$ of our normal controls. With each new variant, we carefully checked for the presence of additional mutations (in the same and other NS-associated genes) and confirmed the variant co-segregated, where parental samples were available, with clinical status within the family. As an example, the P264R variant we observed in NPHS1 (Table 5) has previously been implicated as pathogenic in cases of severe CNS, ${ }^{44}$ however, in a more recent paper it has been classified as a polymorphism. ${ }^{46}$ Often novel (heterozygous) sequence variants were also detected in our ethnically matched control population (Table 4).

We also note that the high rate of consanguineous marriage may make it difficult to estimate pathogenicity of novel mutations without segregation and extended family analysis. However, in silico tools have been used to identify pathogenicity of each of our novel mutations (Table 3).

In families with sporadic NS, the cause of the NS may not be genetic, and screening sporadic cases for known disease genes typically yields fewer results. ${ }^{58}$ Causes of sporadic NS are likely to be a combination of environmental factors together with genetic susceptibility factors.

The molecular genetic diagnosis of NS remains a vital aid to the clinical management of families with NS. It allows for the appropriate long-term management to be undertaken, genetic counseling to be undertaken and where necessary, screening of siblings and other at risk family members. Decisions regarding immunosuppression and transplantation are aided by a molecular genetic diagnosis. It is well recognized that children with causative mutations in NS genes do not respond well to treatment with corticosteroids and other immunosuppressants. ${ }^{5}$

In conclusion, in a Saudi Arabian cohort, $51 \%$ of families with NS were explained by mutations on five known NS genes (NPHS1, NPHS2, PLCE1, MYO1E and CD2AP). NPHS2 gene mutations were the most common molecular genetic cause of NS in this cohort. Unsolved patients from consanguineous families suggest additional novel genetic causes of NS are likely. The genetic heterogeneity of NS, suggests that screening strategies should continue to include multiple NS genes, including rare and recently discovered genetic causes, to allow a high yield of molecular genetic diagnoses. This will then lead to improvements in both precise diagnosis and clinical management.

\section{ACKNOWLEDGEMENTS}

We thank sequencing core facility at Genetics Department at the Research Centre, King Faisal Specialist Hospital and Research Centre for doing sequencing. We also thank the families for participating in the study. We thank the King Khaled Foundation in Riyadh for supporting MH Al-Hamed in this study. JAS is funded by Kidney Research UK and the Northern Counties Kidney Research Fund.
1 Franceschini, N., North, K. E., Kopp, J. B., McKenzie, L. \& Winkler, C. NPHS2 gene, nephrotic syndrome and focal segmental glomerulosclerosis: a HuGE review. Genet. Med. 8, 63-75 (2006).

2 Mundel, P. \& Shankland, S. J. Podocyte biology and response to injury. J. Am. Soc. Nephrol. 13, 3005-3015 (2002).

3 Machuca, E., Benoit, G. \& Antignac, C. Genetics of nephrotic syndrome: connecting molecular genetics to podocyte physiology. Hum. Mol. Genet. 18, R185-R194 (2009).

4 Godefroid, N. \& Dahan, K. Expanding the clinical spectrum of congenital nephrotic syndrome caused by NPHS1 mutations. Nephrol. Dial. Transplant. 25, 2837-2839 (2010)

5 Hinkes, B. G., Mucha, B., Vlangos, C. N., Gbadegesin, R., Liu, J., Hasselbacher, K. et al. Nephrotic syndrome in the first year of life: two thirds of cases are caused by mutations in 4 genes (NPHS1, NPHS2, WT1, and LAMB2). Pediatrics 119 , e907-e919 (2007).

6 Brodehl, J., Krohn, H. P. \& Ehrich, J. H. The treatment of minimal change nephrotic syndrome (lipoid nephrosis): cooperative studies of the Arbeitsgemeinschaft fur Padiatrische Nephrologie (APN). Klin. Padiatr. 194, 162-165 (1982).

7 Kestila, M., Lenkkeri, U., Mannikko, M., Lamerdin, J., McCready, P., Putaala, H. et al. Positionally cloned gene for a novel glomerular protein-nephrin-is mutated in congenital nephrotic syndrome. Mol. Cell. 1, 575-582 (1998).

8 Schoeb, D. S., Chernin, G., Heeringa, S. F., Matejas, V., Held, S., Vega-Warner, V. et al. Nineteen novel NPHS1 mutations in a worldwide cohort of patients with congenital nephrotic syndrome (CNS). Nephrol. Dial. Transplant. 25, 2970-2976 (2010).

9 Putaala, H., Soininen, R., Kilpelainen, P., Wartiovaara, J. \& Tryggvason, K. The murine nephrin gene is specifically expressed in kidney, brain and pancreas: inactivation of the gene leads to massive proteinuria and neonatal death. Hum. Mol. Genet. 10, 1-8 (2001).

10 Benoit, G., Machuca, E. \& Antignac, C. Hereditary nephrotic syndrome: a systematic approach for genetic testing and a review of associated podocyte gene mutations. Pediatr. Nephrol. 25, 1621-1632 (2010).

11 Santin, S., Tazon-Vega, B., Silva, I., Cobo, M. A., Gimenez, I., Ruiz, P. et al. Clinical value of NPHS2 analysis in early- and adult-onset steroid-resistant nephrotic syndrome. Clin. J. Am. Soc. Nephrol. 6, 344-354 (2011).

12 Tsukaguchi, H., Sudhakar, A., Le, T. C., Nguyen, T., Yao, J., Schwimmer, J. A. et al. NPHS2 mutations in late-onset focal segmental glomerulosclerosis: R229Q is a common disease-associated allele. J. Clin. Invest. 110, 1659-1666 (2002).

13 Hinkes, B., Wiggins, R. C., Gbadegesin, R., Vlangos, C. N., Seelow, D., Nurnberg, G. et al. Positional cloning uncovers mutations in PLCE1 responsible for a nephrotic syndrome variant that may be reversible. Nat. Genet. 38, 1397-1405 (2006)

14 Gbadegesin, R., Hinkes, B. G., Hoskins, B. E., Vlangos, C. N., Heeringa, S. F., Liu, J. et al. Mutations in PLCE1 are a major cause of isolated diffuse mesangial sclerosis (IDMS). Nephrol. Dial. Transplant. 23, 1291-1297 (2008).

15 Schumacher, V., Scharer, K., Wuhl, E., Altrogge, H., Bonzel, K. E., Guschmann, M. et al. Spectrum of early onset nephrotic syndrome associated with WT1 missense mutations. Kidney Int. 53, 1594-1600 (1998).

16 Mucha, B., Ozaltin, F., Hinkes, B. G., Hasselbacher, K., Ruf, R. G., Schultheiss, M. et al. Mutations in the Wilms' tumor 1 gene cause isolated steroid resistant nephrotic syndrome and occur in exons 8 and 9. Pediatr. Res. 59, 325-331 (2006).

17 Aucella, F., Bisceglia, L., De Bonis, P., Gigante, M., Caridi, G., Barbano, G. et al. WT1 mutations in nephrotic syndrome revisited. High prevalence in young girls, associations and renal phenotypes. Pediatr. Nephrol. 21, 1393-1398 (2006).

18 Chernin, G., Heeringa, S. F., Gbadegesin, R., Liu, J., Hinkes, B. G., Vlangos, C. N. et al Low prevalence of NPHS2 mutations in African American children with steroidresistant nephrotic syndrome. Pediatr. Nephrol. 23, 1455-1460 (2008).

19 Sako, M., Nakanishi, K., Obana, M., Yata, N., Hoshii, S., Takahashi, S. et al. Analysis of NPHS1, NPHS2, ACTN4, and WT1 in Japanese patients with congenital nephrotic syndrome. Kidney Int. 67, 1248-1255 (2005)

20 Hasselbacher, K., Wiggins, R. C., Matejas, V., Hinkes, B. G., Mucha, B., Hoskins, B. E. et al. Recessive missense mutations in LAMB2 expand the clinical spectrum of LAMB2-associated disorders. Kidney Int. 70, 1008-1012 (2006).

21 Zenker, M., Aigner, T., Wendler, O., Tralau, T., Muntefering, H., Fenski, R. et al. Human laminin beta2 deficiency causes congenital nephrosis with mesangial sclerosis and distinct eye abnormalities. Hum. Mol. Genet. 13, 2625-2632 (2004).

22 Ozaltin, F., Ibsirlioglu, T., Taskiran, E. Z., Baydar, D. E., Kaymaz, F., Buyukcelik, M. et al. Disruption of PTPRO causes childhood-onset nephrotic syndrome. Am. J. Hum. Genet. 89, 139-147 (2011)

23 Kaplan, J. M., Kim, S. H., North, K. N., Rennke, H., Correia, L. A., Tong, H. Q. et al. Mutations in ACTN4, encoding alpha-actinin-4, cause familial focal segmental glomerulosclerosis. Nat. Genet. 24, 251-256 (2000).

24 Palmen, T., Lehtonen, S., Ora, A., Kerjaschki, D., Antignac, C., Lehtonen, E. et al. Interaction of endogenous nephrin and CD2-associated protein in mouse epithelial M-1 cell line. J. Am. Soc. Nephrol. 13, 1766-1772 (2002).

25 Schwarz, K., Simons, M., Reiser, J., Saleem, M. A., Faul, C., Kriz, W. et al. Podocin, a raft-associated component of the glomerular slit diaphragm, interacts with CD2AP and nephrin. J. Clin. Invest. 108, 1621-1629 (2001).

26 Lowik, M. M., Groenen, P. J., Pronk, I., Lilien, M. R., Goldschmeding, R., Dijkman, H. B. et al. Focal segmental glomerulosclerosis in a patient homozygous for a CD2AP mutation. Kidney Int. 72, 1198-1203 (2007).

27 Lowik, M., Levtchenko, E., Westra, D., Groenen, P., Steenbergen, E., Weening, J. et al. Bigenic heterozygosity and the development of steroid-resistant focal segmental glomerulosclerosis. Nephrol. Dial. Transplant. 23, 3146-3151 (2008). 
28 Winn, M. P., Conlon, P. J., Lynn, K. L., Farrington, M. K., Creazzo, T., Hawkins, A. F. et al. A mutation in the TRPC6 cation channel causes familial focal segmental glomerulosclerosis. Science 308, 1801-1804 (2005).

29 Gigante, M., Caridi, G., Montemurno, E., Soccio, M., d'Apolito, M., Cerullo, G. et al. TRPC6 mutations in children with steroid-resistant nephrotic syndrome and atypical phenotype. Clin. J. Am. Soc. Nephrol. 6, 1626-1634 (2011).

30 Brown, E. J., Schlondorff, J. S., Becker, D. J., Tsukaguchi, H., Tonna, S. J., Uscinski, A. L. et al. Mutations in the formin gene INF2 cause focal segmental glomerulosclerosis. Nat. Genet. 42, 72-76 (2010).

31 Mele, C., latropoulos, P., Donadelli, R., Calabria, A., Maranta, R., Cassis, P. et al. MYO1E mutations and childhood familial focal segmental glomerulosclerosis. N. Eng/. J. Med. 365, 295-306 (2011).

32 Sanna-Cherchi, S., Burgess, K. E., Nees, S. N., Caridi, G., Weng, P. L., Dagnino, M. et al. Exome sequencing identified MYO1E and NEIL1 as candidate genes for human autosomal recessive steroid-resistant nephrotic syndrome. Kidney Int. 80, 389-396 (2011).

33 Lemley, K. V. Kidney disease in nail-patella syndrome. Pediatr. Nephrol. 24 2345-2354 (2009).

34 Cohen, A. H. \& Turner, M. C. Kidney in Galloway-Mowat syndrome: clinical spectrum with description of pathology. Kidney Int. 45, 1407-1415 (1994).

35 al Husain, M. \& al Bunyan, M. Consanguineous marriages in a Saudi population and the effect of inbreeding on prenatal and postnatal mortality. Ann. Trop. Paediatr. 17, 155-160 (1997).

36 al-Abdulkareem, A. A. \& Ballal, S. G. Consanguineous marriage in an urban area of Saudi Arabia: rates and adverse health effects on the offspring. J. Community Health 23, 75-83 (1998)

37 Dialysis in the Kingdom of Saudi Arabia. SCOT Data. Saudi J. Kidney. Dis. Transpl. 21, 789-797, 807-816 (2010).

38 Shaheen, F. A. \& Souqiyyeh, M. Z. Current status of renal transplantation in the Kingdom of Saudi Arabia. Transplant. Proc. 36, 125-127 (2004).

39 Kollmar, M., Durrwang, U., Kliche, W., Manstein, D. J. \& Kull, F. J. Crystal structure of the motor domain of a class-I myosin. EMBO J. 21, 2517-2525 (2002).

40 Sali, A. \& Blundell, T. L. Comparative protein modelling by satisfaction of spatial restraints. J. Mol. Biol. 234, 779-815 (1993).

41 Soding, J. Protein homology detection by HMM-HMM comparison. Bioinformatics 21 , 951-960 (2005).

42 Lenkkeri, U., Mannikko, M., McCready, P., Lamerdin, J., Gribouval, O., Niaudet, P. M. et al. Structure of the gene for congenital nephrotic syndrome of the finnish type (NPHS1) and characterization of mutations. Am. J. Hum. Genet. 64, 51-61 (1999).

43 Beltcheva, O., Martin, P., Lenkkeri, U. \& Tryggvason, K. Mutation spectrum in the nephrin gene (NPHS1) in congenital nephrotic syndrome. Hum. Mutat. 17, 368-373 (2001).

44 Koziell, A., Grech, V., Hussain, S., Lee, G., Lenkkeri, U., Tryggvason, K. et al. Genotype/ phenotype correlations of NPHS1 and NPHS2 mutations in nephrotic syndrome advocate a functional inter-relationship in glomerular filtration. Hum. Mol. Genet. 11, 379-388 (2002)

45 Caridi, G., Bertelli, R., Di Duca, M., Dagnino, M., Emma, F., Onetti Muda, A. et al. Broadening the spectrum of diseases related to podocin mutations. J. Am. Soc Nephrol. 14, 1278-1286 (2003).
46 Machuca, E., Benoit, G., Nevo, F., Tete, M. J., Gribouval, O., Pawtowski, A. et al. Genotype-phenotype correlations in non-Finnish congenital nephrotic syndrome. J. Am. Soc. Nephrol. 21, 1209-1217 (2010)

47 Heeringa, S. F., Vlangos, C. N., Chernin, G., Hinkes, B., Gbadegesin, R., Liu, J. et al. Thirteen novel NPHS1 mutations in a large cohort of children with congenital nephrotic syndrome. Nephrol. Dial. Transplant. 23, 3527-3533 (2008).

48 Boute, N., Gribouval, O., Roselli, S., Benessy, F., Lee, H., Fuchshuber, A. et al. NPHS2, encoding the glomerular protein podocin, is mutated in autosomal recessive steroid-resistant nephrotic syndrome. Nat. Genet. 24, 349-354 (2000).

49 Weber, S., Gribouval, O., Esquivel, E. L., Moriniere, V., Tete, M. J., Legendre, C. et al. NPHS2 mutation analysis shows genetic heterogeneity of steroid-resistant nephrotic syndrome and low post-transplant recurrence. Kidney Int. 66, 571-579 (2004).

50 Al-Hamed, M., Sayer, J. A., Al-Hassoun, I., Aldahmesh, M. \& Meyer, B. A novel mutation in NPHS2 causing nephrotic syndrome in a Saudi Arabian family. NDT Plus 3, 545-548 (2010).

51 Huber, T. B., Simons, M., Hartleben, B., Sernetz, L., Schmidts, M., Gundlach, E. et al. Molecular basis of the functional podocin-nephrin complex: mutations in the NPHS2 gene disrupt nephrin targeting to lipid raft microdomains. Hum. Mol. Genet. 12, 3397-3405 (2003).

52 Caridi, G., Gigante, M., Ravani, P., Trivelli, A., Barbano, G., Scolari, F. et al. Clinical features and long-term outcome of nephrotic syndrome associated with heterozygous NPHS1 and NPHS2 mutations. Clin. J. Am. Soc. Nephrol. 4, 1065-1072 (2009).

53 Ruf, R. G., Lichtenberger, A., Karle, S. M., Haas, J. P., Anacleto, F. E., Schultheiss, M. et al. Patients with mutations in NPHS2 (podocin) do not respond to standard steroid treatment of nephrotic syndrome. J. Am. Soc. Nephrol. 15, 722-732 (2004).

54 Gigante, M., Pontrelli, P., Montemurno, E., Roca, L., Aucella, F., Penza, R. et al. CD2AP mutations are associated with sporadic nephrotic syndrome and focal segmental glomerulosclerosis (FSGS). Nephrol. Dial. Transplant. 24, 1858-1864 (2009).

55 Matejas, V., Hinkes, B., Alkandari, F., Al-Gazali, L., Annexstad, E., Aytac, M. B. et al. Mutations in the human laminin beta2 (LAMB2) gene and the associated phenotypic spectrum. Hum. Mutat. 31, 992-1002 (2010).

56 Schumacher, V., Schneider, S., Figge, A., Wildhardt, G., Harms, D., Schmidt, D. et al. Correlation of germ-line mutations and two-hit inactivation of the WT1 gene with Wilms tumors of stromal-predominant histology. Proc. Natl Acad. Sci. USA 94, 3972-3977 (1997).

57 Santin, S., Bullich, G., Tazon-Vega, B., Garcia-Maset, R., Gimenez, I., Silva, I. et al. Clinical utility of genetic testing in children and adults with steroid-resistant nephrotic syndrome. Clin. J. Am. Soc. Nephrol. 6, 1139-1148 (2011).

58 Berdeli, A., Mir, S., Yavascan, O., Serdaroglu, E., Bak, M., Aksu, N. et al. NPHS2 (podicin) mutations in Turkish children with idiopathic nephrotic syndrome. Pediatr. Nephrol. 22, 2031-2040 (2007).

59 Benoit, G., Machuca, E., Nevo, F., Gribouval, O., Lepage, D. \& Antignac, C. Analysis of recessive CD2AP and ACTN4 mutations in steroid-resistant nephrotic syndrome. Pediatr. Nephrol. 25, 445-451 (2010).

60 Schultheiss, M., Ruf, R. G., Mucha, B. E., Wiggins, R., Fuchshuber, A., Lichtenberger, A. et al. No evidence for genotype/phenotype correlation in NPHS1 and NPHS2 mutations. Pediatr. Nephrol. 19, 1340-1348 (2004). 